\title{
Exploring Entrepreneurship amongst the Herero People in Namibia: The Otjinene Village
}

\author{
Wilfred Isak April ${ }^{1}$, Boniface Mutumba ${ }^{1} \&$ Petrus Erwee $^{1}$ \\ ${ }^{1}$ Department of Management Science, University of Namibia, Windhoek, Namibia, Southern Africa \\ Correspondence: Dr. Wilfred Isak April, Department of Management Science, University of Namibia, Private Bag \\ 13301, Windhoek, Namibia, Southern Africa. E-mail: aprilw@lincoln.ac.nz, barros20@yahoo.com
}

Received: April 10, 2014

Accepted: June 10, $2014 \quad$ Online Published: July 4, 2014

doi:10.5430/ijba.v5n4p70

URL: http://dx.doi.org/10.5430/ijba.v5n4p70

\begin{abstract}
Entrepreneurship potential amongst indigenous groups (such as the Herero people in Namibia) should be considered a courageous idea to encourage development in the community and the development of indigenous people within a particular economy. This paper explores the role of indigenous entrepreneurship as it pertains to a Namibian specific indigenous tribe (Herero people in the Otjinene village). It is the argument of the researcher that the diverse Namibian culture could be a distinctive advantage for social and indigenous entrepreneurship, as it makes room for some of the essential traits of an entrepreneur, namely: innovation, creativity, perseverance and self-confidence. An empirical investigation guided by extensive research methods was used to conduct research in Namibia amongst the Herero people in the eastern region (Otjinene Village) of Namibia. These methods are storytelling, in-depth interviews. This paper reveals that Herero people in Namibia have the potential to be indigenous entrepreneurs.
\end{abstract}

Keywords: entrepreneurship, Namibia, innovation, Herero people

\section{Introduction}

The greatest of human endowments as described by Ottih (2000) are intelligence and entrepreneurship, because besides living things, every other thing in the world is a product of human intelligence and entrepreneurship. The concept of entrepreneurship has been defined by various scholars differently across multiple disciplines Schumpeter (1954). To a psychologist, an entrepreneur is one who usually takes a goal directed action for the fulfilment of a particular need. This is usually due to the need to obtain or attain something, to experiment, accomplish or in some instances escape authority from others (Hisrich et al., 2008). However, the purpose of this paper is to explore the entrepreneurial potential amongst a special and unique group of people in Namibia, namely the Herero people in the Otjinene Village. For Namibia as a nation to achieve its Vision 2030, exploring entrepreneurship as grassroots' level will be important for a prosperous economic outlook.

The Republic of Namibia is situated in the south western corner of Africa, bordering South Africa, Botswana and Angola in the North. Namibia is a vast country of 823145 square kilometres, accommodating an estimated 2.3 million people. Namibia is one of the most sparsely populated regions in sub-Saharan Africa, and the rich diversity of its people in culture, language and racial origin is hard to equal. The country has eleven (11) ethnic groups of people namely; Oshiwambo, Okavango, Caprivians, Herero, Khoi-Khoi, Nama, Damara, Basters, Afrikaners, Germans and Coloureds. Most of the ethnic groups have sub-tribes who speak local dialects. This paper will explore the entrepreneurial initiatives of the Herero people who reside in the Otjinene village.

This paper is a result of ethnographic research conducted by the author among the Herero people in Namibia in the Otjinene village. First the paper will give an account on the Western literature; thereafter a brief history about the Herero people in Namibia will be outlined. This will be followed by the context of indigenous enterprises in Namibia (the Otjinene village), methodology, and discussion reflecting back on the literature, conclusion and recommendations.

\section{Exploring the Importance of the Problem}

Entrepreneurship amongst the Herero people in Namibia is worth exploring, as the country is in need of producing entrepreneurs for the success of its economy. Entrepreneurial success stories on the African continent are prominent amongst the "Yoruba women" in Nigeria and it is important the Namibia learns from these best practice models (A. 
Ajayi, personal communication, January 28, 2014). It is a known trend in the entrepreneurship literature to discuss entrepreneurship mostly in terms of corporate entrepreneurship. However, in this twenty first $\left(21^{\text {st }}\right)$ century due to globalisation there has been an increase interest amongst scholars in the developed and developing world to look into the quality and depth of issues pertaining to indigenous people (Anderson and Giberson, 2004). Recently, ground-breaking research in terms of how scholars view indigenous entrepreneurship, the role of small firms in fostering economic development (mostly with regard to creation of self-employment and self-determination) and the rationale for fostering an entrepreneurial culture has been published. Few exploratory studies pertaining to entrepreneurship with reference to Namibian Herero people has been identified to date. This exploratory paper is the first of its kind to be conducted by a Namibian on Namibian soil.

Academic research related to entrepreneurship as a general concept in Namibian is rare to find, with no studies looking into indigenous entrepreneurial taking amongst the Otjiherero people in the Otjinene village in Namibia. This problem is worth exploring due to a lack of skilled people in the area of entrepreneurship in Namibia (Africa), although the government of Namibia is trying to encourage all citizens to get actively involved in entrepreneurial initiative's, acknowledging the fact that resources are limited (V. Ankama, personal communication, November 10, 2008).

When Namibians engage in entrepreneurial activities they will secure a better future for tomorrow, but it has been a challenge for communities in the Otjinene village as they have limited access to employment opportunities and lose motivation during their free time. Therefore, an increasing number of people in villages such as Otjinene indulge themselves in delinquent activities such as stealing and drug, alcohol and substance abuse. They become isolated and have little or no hope for the future. The people who lose hope are mostly the young people of the Otjinene village whom are viewed as the leaders of tomorrow as indicated in the World Bank Reports. It is unfortunate that the potential of young people is often obscured by concerns with the anti-social activities of some young people as a response to their economic and social situation.

According Ahmed (1993), people should be viewed as an essential human resource, which has edge over the physical resources in contributing to the development, as human resources will in turn make use of the physical resources. For the people in the Otjinene village to fully develop their entrepreneurial potential an investment in human capital is required. Most of the innovative and creative ideas amongst the Herero people in Otjinene are deeply embedded in their cultural values. The researcher is of the opinion that when people are skilled and their aspirations and drives are met, they can play an important role in the development of their community, in fact also for the well-being of a larger Namibian economy.

It is relevant to argue at this point in time that most entrepreneurship research does not take into account the fact that physical and human resource complement each other and, in particular, in indigenous communities where capital investment is very low, their core strength is in human resources, in particular the traditional skills people possess and their indigenous knowledge. This paper intends to address this gap of limited research amongst indigenous people in Namibia (in particular the Herero people) with regard to human resource potential, in particularly the views of the Otjinene people, as it pertains to entrepreneurship. The next section of the paper will look at the review of related literature.

\section{Review of Related Literature}

Entrepreneurship is of growing interest in both the developing and developed world. Nowadays the first people (as we also refer to them as indigenous people) talked about indigenous entrepreneurship. Indigenous people refer to the Canadian First Nations, Maori People of New Zealand and the Aboriginal People of Australia. Indigenous people are defined by language, ancestral history or any people who occupied a particular territory before the arrival of the settlers (Dana, 2005). In the Namibian context we will refer to the Khoi-Khoi people as indigenous people for the purpose of this paper. The Khoi-Khoi people have a close link with the Namibian Herero people. Numerous studies pertaining to issues related to indigenous entrepreneurship indicated that many countries on the African continent see development of entrepreneurship as the primary route to achieve industrialisation and economic development. According to Peredo et.al (2004) indigenous people from around the world have suffered greatly over the years, from chronic poverty, lower education and poor health. Given this background, entrepreneurial issues amongst Namibian Herero people become critical to look into. The roots of the concept emerged in the thirteenth century, and originated from a French word, "enterprendre", which refers to taking one's own hand and do something (Venter et.al. 2008). In the middle ages the term entrepreneur was used to describe both an actor and a person who is able to manage large production projects. Large production projects did not usually give the entrepreneur room to take risks, but simply managing the projects using the resources provided by the state. In the eighteenth $18^{\text {th }}$ century the concept of 
entrepreneurship was introduced in the business context and Richard Cantillon (1755), a French economist was the first to discuss entrepreneurs as risk takers. Other prominent scholars such as Say and Mill in Nieman et.al. (2003) also linked entrepreneurship to risks. Cochran in Nieman et.al. (2003) continued to view an entrepreneur as a risk taker. Shapero and Saskol in Nieman et.al. (2003) found that in most definitions of entrepreneurship, there is an agreement that we are talking about the kind of behaviour that includes the acceptance of risks.

It is the argument of Zaleznik and Kets de Vries that an entrepreneurial personality includes "the urge to take risks", and the stubborn resistance to change. Except the risk component new views on entrepreneurship emerged in the nineteenth $\left(19^{\text {th }}\right)$ century in which entrepreneurship is viewed as comprising of special skills and traits (Nieman et al. 2003). The growing interest of entrepreneurs as agents of change was bolstered by the theoretical work of Joseph Schumpeter in the twentieth $\left(20^{\text {th }}\right)$ century. Schumpeter was an Austrian economist who provided deeper insights by linking the theory of entrepreneurship to economic change (Schumpeter, 1954: 131-142). It was the notion of Schumpeter that economic growth does not necessarily arise from capital accumulation, but from innovation and creativity. He argued that equilibrium is predominant in an economic system. After realising that innovation is critical for growth Schumpeter realised that innovation has to be implemented by someone, and the ability to break with established practice was primarily related to individual entrepreneurs. A critical dimension of entrepreneurship in the Western literature is that it demands a specific type of personality, which can be viewed differently to that of an ordinary person. Exploratory ethnographic research such as this (of Herero people) can add substantially to the academic literature on entrepreneurship. The next section of this paper will look into the history and cultural background of the Namibian Herero people.

\section{History and Cultural Background of the Namibian Herero People}

Hereroland with less than 150000 inhabitants, covers an extensive area of 44756 square kilometres. The area known as Herero land East (Otjinene, Otjozondjou and Omongwa) forms part of the present Omaheke region in central eastern part of the country. Topographically Hereroland forms part of the northern Kalahari zone, which is a flat, sandy region with permanent dunes in the eastern part. As nomadic pastoralists, the Herero people wandered across large tracts of land after embarking on their southerly migration from Kaokoland during the middle of the eighteenth $\left(18^{\text {th }}\right)$ century. Numerous wars against the Nama as well as the German forces, further contributed to the dispersal over a vast area stretching from Damaraland in the west to the Botswana border in the east, and even beyond. It is clear that these events together with extensive acculturation have exerted tremendous influence on the lifestyle and the entrepreneurial culture on all spheres of national life (Malan, 1995).

After residing in Kaokoland and adjacent parts of the Republic of Angola for almost two decades, severe drought caused the Herero people to migrate south. The marginal habitat of Kaokoland's semi-arid grasslands was such a nature that it could not withstand the detrimental effects of overgrazing and overpopulation, thereby further necessitating the migration. As a reasonable number of Otjiherero people settled in the central parts of the country, conflict with the Oorlams from Vaalgras, who were moving in the northerly direction from the Cape Province, became inevitable (Malan, 1995). In 1830, the first clash between the Herero people and the Oorlam Chief Jonker Afrikaner occurred in the vicinity of the present Windhoek. Jonker's dream of a powerful empire north of Windhoek eventually induced him to break a treaty which he had earlier signed with Hugo Hahn under the influence of the missionaries. This was a fierce attack on the Herero people of Okahandja, and many people lost lives and a large number of cattle were seized. The years which followed the raids had to be continued, because Jonker settled his heavy debts for liquor and merchandise with Herero cattle. The next section of this paper will look at the Otjinene village.

\section{The Otjinene Village}

Otjinene village is situated three hundred and forty kilometres (340 from) Windhoek. As the researcher drove into the village, from a distance the communities could be noticed in full swing busy with their daily entrepreneurial activities. These activities amongst many others include the herding of cows, self-set up local jewellery and ornament shops which disappear during the light nights, and all the roads are cleared as if there were no business activities during the day. It is important to highlight at this point in time that Otjinene is a living village by day and night. Furthermore, school kids can be noticed at a distance going for their first "uit naweek" (weekend away from boarding school) with suitcases on their heads in straight line with barefoot to local cattle post nearby. Most people in the Otjinene village are constantly engaged in an entrepreneurial act without been fully aware. The paper will look into the context of enterprise in the next section. 


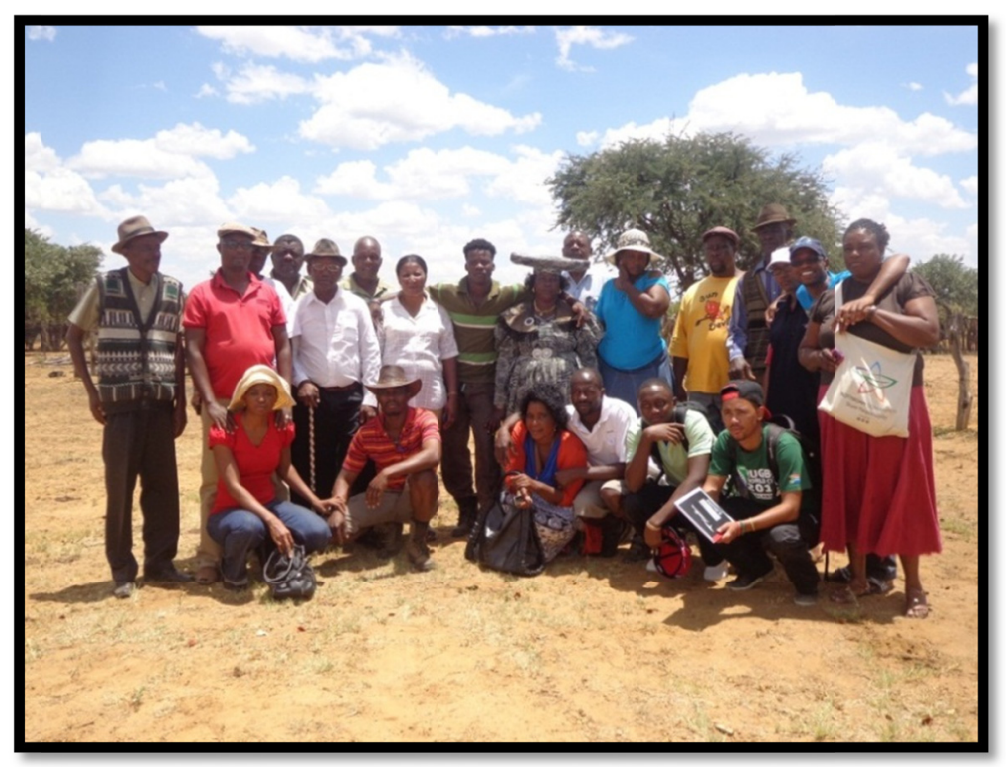

Figure 1. Researcher with community members

\section{The Context of Enterprise of the Herero People}

Traditionally the Herero pastoralists followed a nomadic lifestyle with their large herds of cattle, as some of their kinsmen in Kaokoland still do today. Cattle especially the cow describes the Herero person and carries significant meaning for them. Nowadays, nomadic movements of the Herero people are restricted as most people have now erected permanent dwelling places. To cope with the limited availability of water and grazing they move to cattle posts as an alternative. Young men often have the tasks to move with the cattle to utilise seasonal grazing, but they always return to the main village after a few months when grazing conditions improve (G. Basson, personal communication, 15 October 2013).

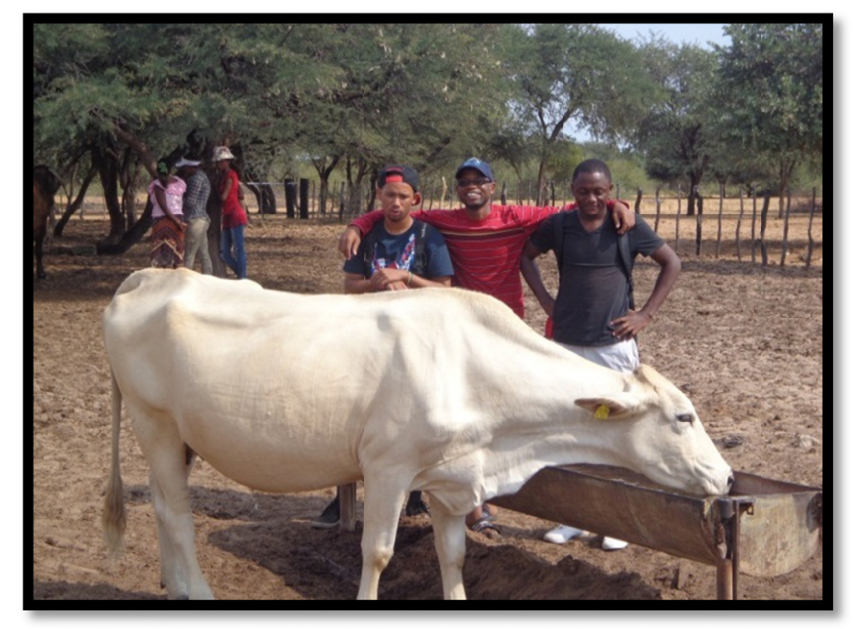

Figure 2. Observing animals in the early hours of the morning 


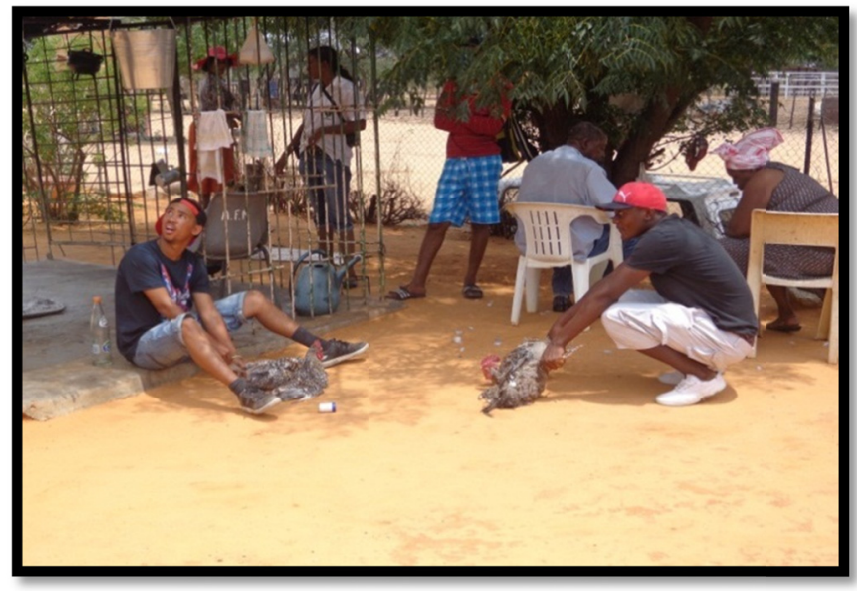

Figure 3. Chickens are also slaughtered for income in Otjinene

Since cattle can indeed be described as the life of the Herero people, strict control measures are enforced to protect the interest of all parties concerned. Large-scale estrangement of stock is usually not permitted because there are people whose material welfare is at stake, and others who live with the hope of inheriting enough cattle to enable them to make a living or survival. The management of livestock is based on the principle that there is no private ownership of cattle in the true sense. The inheritance of livestock is an important and critical dimension in the lives of the Herero people. An external factor that is exerting a far-reaching influence on the economic life of the Herero people is the high degree of acculturation to which they have been exposed. To a certain degree the whole technology has been extensively conformed to that of the European culture, with which they have been in contact for centuries. Most of the Herero women still wear the Victorian-style dresses introduced by the wives of the German missionaries, and furnishing and construction of their houses have undergone major changes.

Despite significant changes offered through the modern technology, education and training, most Herero people still cherish far above anything else the idea of people being cattle farmers. This is one of many reasons and some even unknown that they do not offer services on the labour market, but this does not mean that they are not entrepreneurial. They have deeply inherent characteristics that could make them outstanding entrepreneurs. In the next section of this paper we will discuss the methodology use to carry out this study.

\section{Methodology}

Although countless developing country perspectives on entrepreneurship has been written, this paper is unique in the sense that it looks into an ethnic community who make their livelihood from cattle (livestock). This paper aims to explore the entrepreneurial activities of the Herero people in Namibia. In order to contextualise and understand the entrepreneurial activities of the Namibian Herero people it was first critical to explore and understand the basic entrepreneurial concepts by means of literature. To ensure that validity is enhanced, triangulation of methods was deemed as essential. Triangulation of methods is quiet often used in social sciences and business research because it gives the research observer the chance to observe the activities unfolding in the communities at first hand (Asika, 1991). Purposive sampling techniques were used within the village of Otjinene, because there were specific farmers whom the researcher targeted. This was deliberately done. The researcher also interviewed local small medium enterprise owners randomly. In total 50 (fifty) people have been interviewed in the Otjinene district. This sample constitutes farmers, small scale entrepreneurs and young unemployed people (Table 1.1 shows breakdown of respondents).

Table 1. Respondents groupings

\begin{tabular}{ll}
\hline Group & Total Number \\
\hline Farmers & 20 \\
\hline SME owners & 20 \\
\hline Unemployed youth & 10 \\
\hline TOTAL & $\mathbf{5 0}$ \\
\hline
\end{tabular}


An in-depth literature review coupled by participant observation and in depth oral interviews was conducted with the Herero people in Otjinene. Participant observation was an effective method to carry out this research as significant meaning is carried by the Herero people through unspoken and written text. Oral interviews gave the researcher first-hand cultural experience about the spoken words of the Herero people.

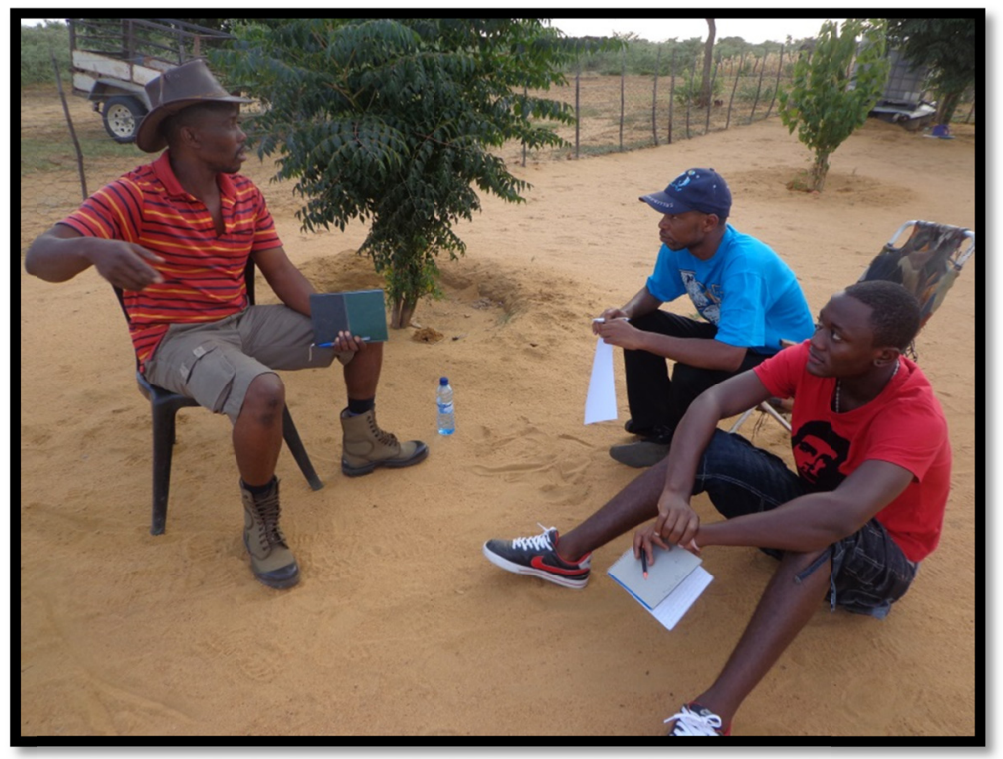

Figure 4. Community interviews in Otjinene

\section{Findings on the Herero People in Terms of Academic Literature}

Entrepreneurship from its definition in the thirteenth century means, it is the process by which people take their hands and "do something". As we scanned through the literature review of this paper it is clear that entrepreneurship has been associated with the risks component as was highlighted by Schumpeter. The findings of this paper in terms of the related literature indicates that entrepreneurship in the Namibian Herero context should be viewed in terms of the manner in which individuals within the Otjinene village strive for their personal development through farming for their own benefit and those around them. Most of the people interviewed felt that risk taking is a critical component for famers in the Otjinene village, as you constantly do not know when the cows could get sick or when the next rainfall will fall. If we reflect back to the literature (in Section 3) Richard Cantillon (1755) talks about the essence of taking risks as an entrepreneur. There is a strong similarity in terms of the way that entrepreneurship is viewed in terms of the literature in (Section 3), and the findings from this study in the Otjinene village. It can be noted in the literature that innovation is generally affected by personal factors such as tolerance, ambiguity and risks taking. In order to cope with these latter mentioned factors people in Otjinene needs assistance in dealing with issues of ambiguity, self-confidence as they find themselves in vulnerable situations in their day to day lives. Giving guidance and assistance is very important as most of the farmers in Otjinene do not own many livestock to make them full-fledged entrepreneurs. It is clear that the Namibian Herero people are cattle farmers, and are less concerned about selling their livestock on a flea market. However their entrepreneurial spirit and potential is evident through their determination to move around with livestock through severe drought conditions. In terms of entrepreneurial personality traits risk taking is also prominent. Strong traits of social entrepreneurship are evident in reality as is reflected in the literature. The primary motive is not necessarily profit, but that livestock has to be inherited and carried over across generations. However, as the researcher engaged in lengthy discussions with some respondents there is also a strong sense of mistrust amongst them. This is mostly as a result of jealousy. Other factors posing major challenges to indigenous entrepreneurs in Otjinene are lack of capital, inadequate support from the Namibian government and a poor market to sell their locally produced products and services. Another critical point highlighted by the indigenous entrepreneurs in Otjinene is that even if loans are available the collateral is extremely high and farmers will be unable to gain access to funding. Changes in technology and education have brought a number of changes to the lifestyle of the Herero people, but they have a culture which is deeply embedded which at all times requires finding a balance between entrepreneurship and business. From the ethnographic study it is clear that the 
Herero people have deeply embedded entrepreneurial cultural traits. In summary if we look back on the literature and the illustrative framework, it is undisputable that culture has an impact on how the people in Otjinene views entrepreneurship and a collaboration between the rural and urban communities is required to change the current situation in which the Otjinene people find themselves.

\section{Conclusion and Recommendations}

It is no doubt that development of indigenous entrepreneurial activities in Namibia will sustainably improve the economic and social standing of the nation. For any entrepreneurial activity to be a success it relies strongly on the entrepreneurial spirit of the individuals within the community. Through this exploratory study it is evident that the community has strong inherent entrepreneurial traits, but will need training in the areas of planning, business skills and how to best build lasting trust relationships. These qualities will certainly enhance community spirit to build sustainable enterprises.

In the absence of abundant resources, Namibia Herero people view entrepreneurship as the ability of a Herero men or women to own cattle (cows). Although not the entire community is highly educated the Herero people perform entrepreneurial functions guided by their culture. Although they do not perform the entrepreneurial functions in an open marketplace, they perform their entrepreneurial functions within their clan and extended family through inheritance. This explains the deeply cultural embedded entrepreneurial traits of the Herero people. Given their strong belief in cultural rituals they are one of the few ethnic groups that could succeed in business while maintaining their culture at the same time which could be carried over across generations.

\section{References}

Ahmed, M. (1993). Growth of Industrial Entrepreneurship in Bangladesh; A study of Bank Finance Engineering Industries, a PHD thesis (unpublished, Institute of Bangladesh Studies, University of Rajshanir)

Asika, N. (1991). Research Methodology in the Behavioural Sciences. Lagos. Longman Nigeria.

Hisrich, R.D., Peters, M.P., \& Shepard, D.A. (2008). Entrepreneurship ( $7^{\text {th }}$ International Edition). McGraw-Hill.

Malan, J.S. (1995). The Foundations of Ethnicity and some of its current ramifications in Namibia. Africa Insight, 23(4). Pretoria: Africa Institute of South Africa.

Nieman, G., Hough, J., \& Nieuwenhuizen, C. (2003). Entrepreneurship. A South African Perspective. Van Schaik Publishers. Pretoria.

Otihh, L.O. (2000). Entrepreneuring. Towards Preparedness. Port Harcourt: Pearl Publishers.

Peredo, A. M., Anderson, R.B, Galbraith, C.S., Honig, B., \& Dana, L.P. (2004). Towards a theory of Indigenous Entrepreneurship. International Journal of Entrepreneurship and Small Business, 1(1/2). http://dx.doi.org/10.1504/IJESB.2004.005374

Schumpeter, J.A. (1934). In Dana, L.P. (2005). Towards a Multidisciplinary definition of Indigenous Entrepreneurship. P.3. Great Britain, MPG Books, Bod min, Cornwall. 